\section{BurbuCar, Lina Toro La obsesión por la línea}

BurbuCar, Lina Toro. The obsession for the line
Resumen Burbucar, de la arquitecta Lina Toro, es un proyecto de limpieza y precisión de un programa existente, en el que se reconoce como una preexistencia a mantener la linealidad espacial. Esta característica esencial es tratada como concepto arquitectónico, al develar el traspaso desde el plano al espacio, de una idea al proyecto.

\title{
Javiera Barrientos
}

Palabras Clave

Proyecto

Línea
Color

Habitabilidad

Obsesión

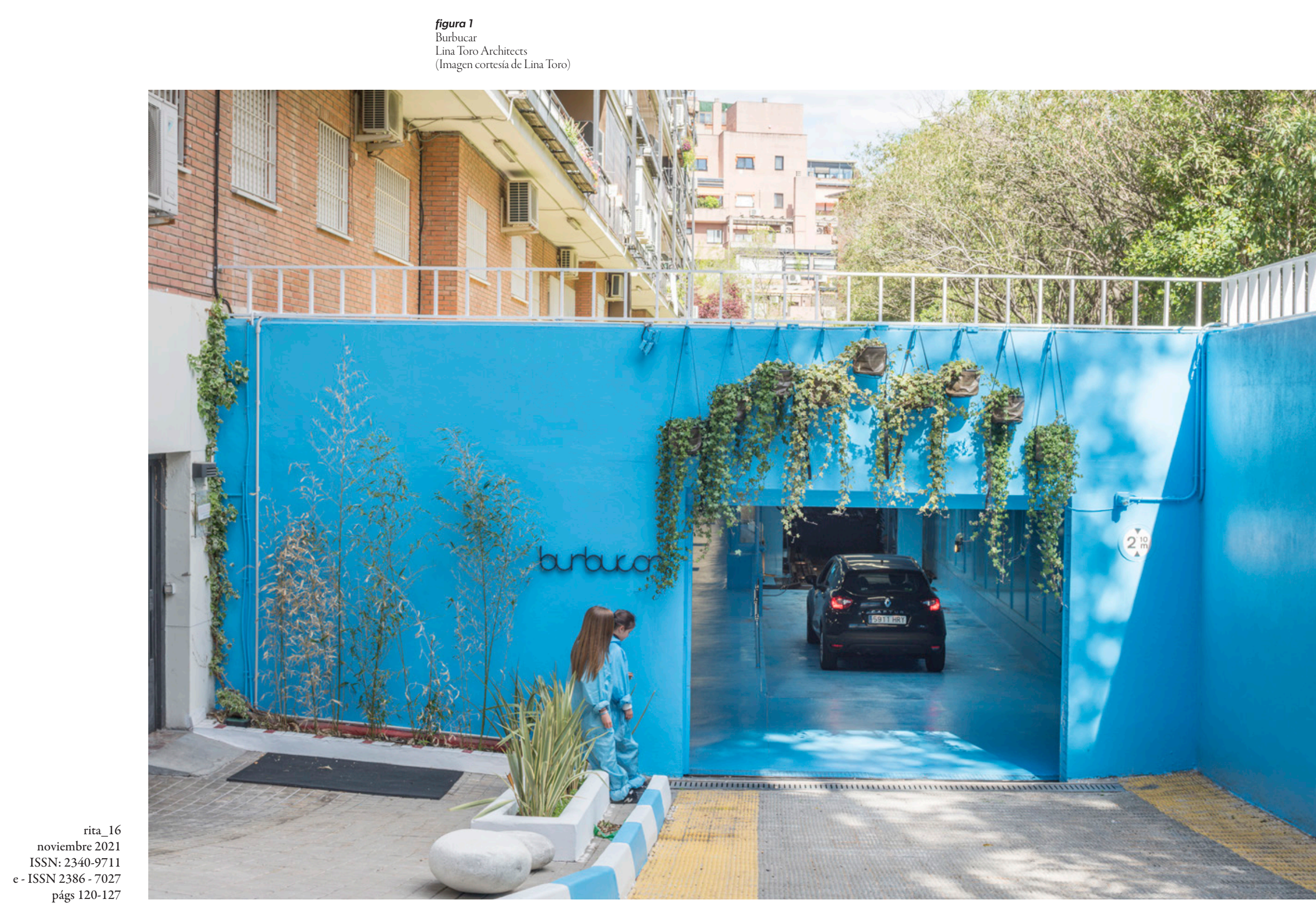




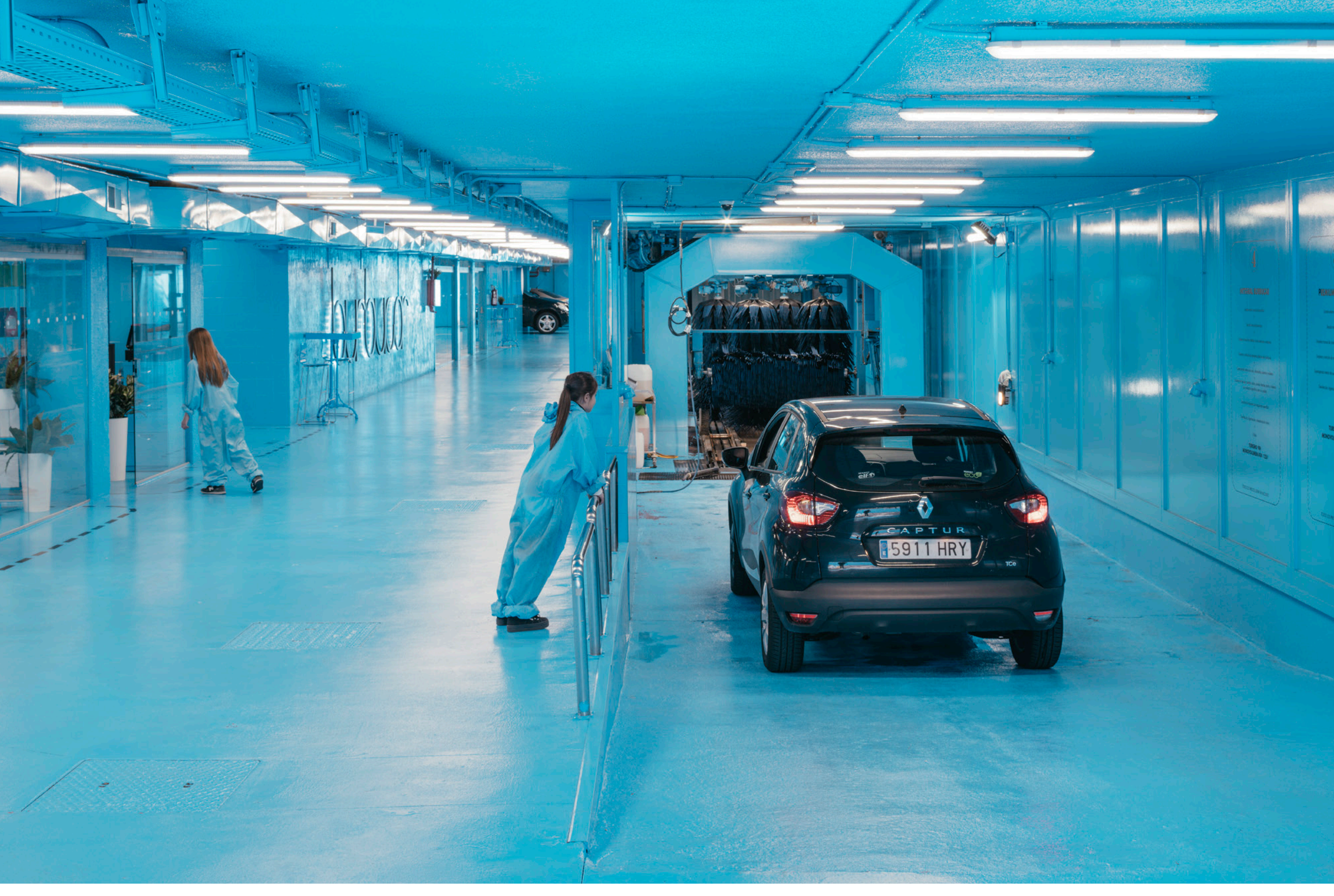




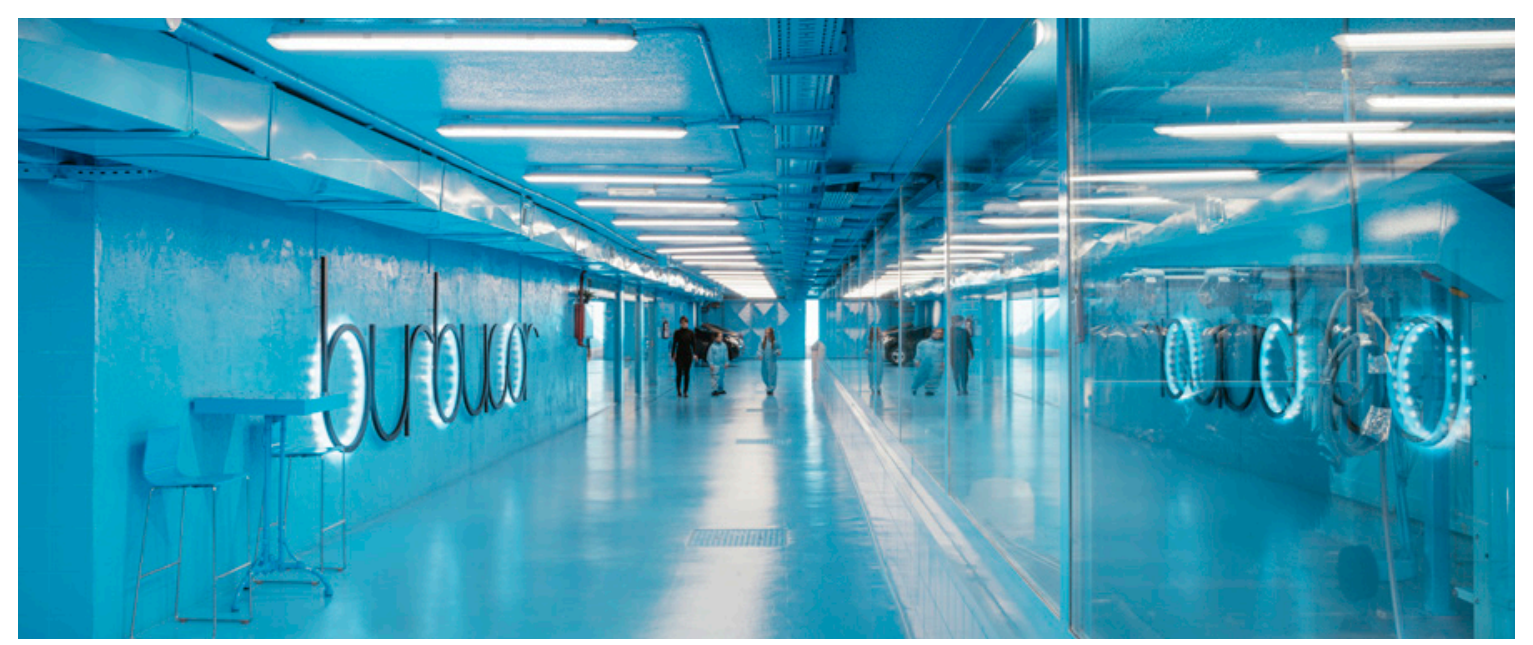

figura 2
Burbucar

Lina Toro Architects
(Imagen cortesia de Lina Toro)

En una entrevista, la artista japonesa Yayoi Kusama explicaba que su inspiración basada en los puntos respondía a una obsesión infinita que se le fijo desde pequeña ya que "cuando pintaba encontraba el mismo patrón en el cielo raso, escaleras y ventanas como si estuviera en todos lados" (Kusuma: 2013). Reconocida mundialmente por vincular el trastorno obsesivo compulsivo que padece con su producción artística, Kusama acude a la obsesión para ser su fuente de inspiración, así como el catalizador y la imagen final de su obra: la manifestación de que una idea repetitiva sirve para producir un objeto repetitivo.

Si comprendemos la obsesión como una idea o imagen fija que determina una actitud o acción, es decir no es posible operar desde otro criterio pues la obsesión persiste por sobre la voluntad del sujeto, el proyecto de Burbucar de Lina Toro puede ser reconocido como arquitectura que nace de una obsesión: la imagen de forma obsesiva que fue transformada en concepto, habitabilidad y elemento arquitectónico es la línea.

En una primera mirada, Burbucar aparece como un plano parejo de color cian que se obtuvo a partir de la utilización de pintura poliuretano, la cual se aplicó en todas las caras interiores de un espacio longitudinal bajo tierra de 70 metros de largo y 12 de ancho: un túnel monocromo con saturación polarizada. En donde, la intensidad máxima está definida por la alta pigmentación del color interior, mientras que la mínima

El túnel fue rediseñado a partir de la comprensión de las características esenciales del espacio disponible: tensión y profundidad. La primera se identifica gracias a la división longitudinal- siendo una preexistencia espacial: el lavado de autos que ya funcionaba en el lugar tenia esta distribución espacial- la cual se redefine y potencia mediante la higenización de las tres instancias secuenciales: en un borde se mantuvo el lugar en donde se lavan los automóviles, en el otro borde se emplazan las zonas de espera de los conductores y en el medio se mantuvo el espacio mixto de coexistencia entre vehículos y personas. La habitabilidad en tensión longitudinal, si bien es una condición espacial, aparece por una decisión estética pues aparece claramente por el uso de un único color.

Por otro lado, las decisiones tomadas para definir la iluminación interior construyen la condición de profundidad en conjunto con el carácter del espacio monocromático. Los extremos del lava autos abiertos permiten el ingreso de luz solar obteniendo el efecto de luz al final del camino: se destaca el umbral de acceso y salida únicamente en el espacio vehicular unidireccional. Mientras que a nivel de cielo se ubican las luminarias de forma transversal, configurando dos franjas paralelas que refuerzan la condición en secuencia del espacio y duplican la división espacial de tres a seis.
Para luego ser duplicada nuevamente gracias al efecto de la pintura brillante que refleja la luz tanto en los muros longitudinales como en el pavimento.

Sin embargo esta duplicación no es una condición solo espacial, sino que también se da en la habitabilidad gracias a la idea de estar en el interior de un espacio escenográfico dual. Tanto las salas de espera como la franja de lavado de autos, poseen un carácter de espectáculo en los que se fusiona la arquitectura con la perfección de la máquina teatral: el escenario no solo esta situado en la franja frente al "espectador, para ver, para la recepción de la representación. Es suficiente trasladar el lugar del así llamado juego a un lado (...) para que se convierta en una cosa extraña" (Kantor, 1974: 44) con lo que se proyectaron dos escenografias enfrentadas. La secuencia de limpieza deja de ser tratada únicamente como un lugar funcional para ser presentada como una performance en donde las personas pueden contemplar- por un poco menos de media hora- como se remueve la mugre indeseada de sus vehículos, mientras se sientan en sillas transparentes colgantes junto a pequeñas piscinas con pelotas, rodeados plantas de diferentes tamaños, o en un mobiliario metálico junto a varios productos de limpieza.

\section{Javiera Barrientos}

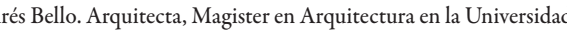
Catolica de Chile. Se desempeña como docente vinculada al área de Teoría, Representación y Taller. Desde el año 2018 realiza una pasantia creativa dirigida por Nano Pulgar y Claudia Betancourt, en WALKA: Art Design Jewelry Studio

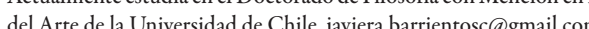

Todo lo anterior devela que Burbucar es la manifestación espacial de una obsesión, una imagen fijada en el espacio que recoge Lina Toro y potencia mediante la limpieza y definición de un lugar monocromático, pues comprende qué la línea es "como si estuviera en todos lados". El habitar se proyecta a partir de una secuencia en línea recta que pareciera responder a una planta esquemática de relaciones longitudinales continuas, pues "la ley del edificio está escrita en el suelo" (Sacriste, 1959: 2). Los elementos construidos responden al espesor de cada linea, la cual es interpretada construyendo un sistema de pesos visuales, en donde lo pesado se arraiga al piso y se levantan los elementos secundarios y más livianos. Mientras aparecen líneas segmentadas en el pavimentoque recuerdan la idea de un plano- para precisar el lugar en donde permanecen de forma separada las personas y los automóviles. La condición obsesiva por el orden y el control de forma lineal se exacerba de tal manera en que "la precisión de esos elementos no es natural" (Diaz, 2019: 73) obteniendo un espacio coordinado en tiempo real: una coreografía de la vida en cian.

\section{Bibliografía}

DIAZ, Francisco (2019). Patologías contemporáneas: ensayos de arquitectura tras la crisis de 2008. Santiago: Uqbar ediciones

KANTOR, Tadeusz (2009). La clase muerta: Wielopole, Wielopole. Barcelona: Alba Editorial. [Titulo original: Umarla Klasa, Wielopole, Wielopole, 1974].

SACRISTE, Eduardo (1959). Building Footprints: A Selection of Forty-Five Building Plans, All Drawn at the Same Scale. Carolina del Norte: The Student Publication of the School of Design. Rietti, M. [Museo Malba]. (2013, 9 de agosto). Yayoi Kusama: Una conversación con Philip Larratt-Smith [Video]. YouTube. https://www. youtube.com/watch?v=lkoQf8rEfyc 
